\title{
Inflammatory Markers: Pentraxin 3, Interleukin10 and Interleukin18 in Children with Chronic Kidney Disease
}

\author{
Fatina I Fadil', Samar M Sabry', Rasha E E Galal ' , Abbas A Mourad², \\ Mohamed G Shouman', Mahmoud Tarif Hamza ${ }^{3}$ and Hassanin M.Hassanin ${ }^{2}$ \\ 1- Department of Pediatrics, Faculty of Medicine, Cairo University, Cairo, Egypt. \\ 2- Department of of Pediatrics, National Research Centre, Giza, Egypt. \\ 3- Department of Clinical Pathology, National Research Centre, Giza, Egypt.
}

\begin{abstract}
Introduction

Inflammation is a major risk factor for cardiovascular $(\mathrm{CV})$ complications and mortality in patients with ESRD. Patients with end stage renal disease (ESRD) strongly exhibit higher serum levels of inflammatory cytokines compared to healthy individuals.
\end{abstract}

\section{Patients \& Methods}

The serum levels of proinflammatory cytokine IL-18, and anti-inflammatory IL-10 and of Pentraxin 3 were studied in sixty pediatric patients, aiming to compare the inflammatory status of children with end-stage renal disease on hemodialysis and those on conservative treatment; and to study the effect of vascular access and cardiac disease on those cytokines. Thirty patients had end stage renal disease on regular hemodialysis in Pediatric Nephrology Unit, Cairo University Children's Hospital, fifteen patients had chronic kidney disease, on conservative therapy, in addition to fifteen healthy matched controls.

\section{Results}

The mean age of patients and duration of dialysis for the hemodialysis group was $11.93 \pm 3.79$ and $6.03 \pm 2.46$ years respectively while the other group was $8.46 \pm 3.63$ years. Hemodialyzed patients had significantly higher post dialysis levels of Pentraxin 3 and interleukin 18 compared to pre dialysis levels with p value of 0.044 and 0.001 respectively. There was no difference regarding pre and post dialysis levels of interleukin10. Hemodialyzed patients had higher levels of Pentraxin3 and interleukin 18 than conservative patients with $\mathrm{P}$ value of 0.006 and 0.01 respectively. Pentraxin 3 and interleukin 18 were higher in patients who dialyzed via central venous catheters than via Arteriovenous fistula with $\mathrm{P}$ value of 0.04 , 0.002 respectively; while interleukin 10 was lower with $\mathrm{P}$ value of 0.03 .

\section{Conclusion}

Children with ESRD had higher post dialysis levels of inflammatory cytokines such as PTX3 and IL 18 than pre-dialysis levels. Also, they had higher levels than conservative patients. No significant difference as regard IL10 in both hemodialysis and conservative patients. IL10 was negatively correlated with cardio-vascular complications. Fourty percent of patients had cardio-vascular lesions proved by ECHO. The use of central venous catheter in HD patients is associated with increase in inflammatory markers. PTX3, IL18 were significantly higher in patients who dialyzed via CVC than those via A-V fistula.

\section{Key words:}

End stage renal disease, inflammatory markers, hemodialysis, Interleukin18, Interleukin10, Pentraxin 3

\section{Correspondence:}

Rasha Essam Eldin Galal

Department of Pediatrics, Faculty of Medicine, Abu el Rish Children's hospital Cairo University, Cairo, Egypt. Email: raschaessam@yahoo.com

\section{geget : The Journal of the Egyptian Society of Pediatric Nephrology and Transplantation (ESPNT) geget https://geget.journals.ekb.eg/ Published by ESPNT http://espnt.net/ Cohosted by Egyptian Knowledge Bank https://www.ekb.eg}




\section{Introduction}

Chronic kidney disease (CKD) can be present when there is a reduction of GFR $<60 \mathrm{ml} /$ minute $/ 1.73 \mathrm{~m}^{2}$ [1]. Progression of CKD is also present when there is a decrease in eGFR of $>5 \mathrm{ml} /$ minute $/ 1.73 \mathrm{~m}^{2}$ within one year or $>10$ $\mathrm{ml} / \mathrm{minute} / 1.73 \mathrm{~m}^{2}$ within five years [2]. When GFR is > $60 \mathrm{ml} /$ minute $/ 1.73 \mathrm{~m}^{2}$ in patients with CKD without evidence of renal damage, it needs no further assessment. ESRD is regarded as a prototypical situation of chronic inflammatory state, which favors atherosclerosis, subsequent cardiovascular disease and increased mortality. Identification of inflammatory markers, and determination of their predictive power is important for risk stratification in ESRD [3].

Pentraxins are soluble proteins and are considered a group of multifunctional proteins that have a cyclic multimeric structure. They are made up of two groups, short and long ones. The two short pentraxins are $\mathrm{C}$ reactive protein and serum amyloid $\mathrm{P}$ component. Pentraxin 3 is the protein in the long PTX group, it differs from the short group by the N-terminal domain, cellular sources, gene organization and recognition of ligands [4]. Pentraxin 3 levels are higher in vascular disorders including autoimmune diseases such as small vessel vasculitis and myocardial infarction [5]. It represents a marker of vascular bed involvement while the exact mechanisms responsible for its pathogenesis are not known [6]. It is considered the earliest inflammatory marker that can be assessed. The normal level is up to $1.5 \mathrm{ng} / \mathrm{mL}$ which is measured by a monoclonal antibody. Its level correlates with the clinical diagnosis and disease activity [7].

Interleukin 18 belongs to IL-1 family, is produced by macrophages and other cells and acts by binding to the IL18 receptor. It is a pro-inflammatory cytokine, which together with IL12 induces cell mediated immunity following infection with microbial products like lipopolysaccharide [8]. Its combination with IL12 also known to inhibit Imunoglobulin E and ImunoglobulinG1 release and enhance $\operatorname{IgG} 2 \mathrm{a}$ production in B cells. IL18 binding protein (IL18BP) reacts with IL12, so it can regulate its biological activity [9]. IL-eighteen's proinflammatory properties include stimulation of nuclear factor- kappa B. Increased expression is also present with wide range of autoimmune diseases such as encephalomyelitis, lupus nephritis and rheumatoid arthritis and induction of pro-inflammatory mediator release such as (IL1, chemokines), tumour necrosis factor [10].

Interleukin 10 is an anti-inflammatory cytokine, its action is mediated through a complex of two receptors which are (IL10R1) and IL10R2. After, ligand binding, it enables signal transduction. So, the functional receptor contains a dimer of heterodimers of IL10R1 and IL10R2 [11]. IL10 inhibits DC maturation and its differentiation from monocyte precursors. Thus, many of the immunoinhibitory actions of IL10 can be referred to its effect on the antigen presenting cells to inhibit the production of $\mathrm{T}$ helper1 (subtype of $\mathrm{T}$ lymphocytes) associated cytokines IL2, interferon- $\gamma$, IL-4 and IL-5 [12]. The serum levels of proinflammatory cytokine IL-18, and anti-inflammatory IL-10 and of Pentraxin 3 were studied in sixty pediatric patients, aiming to compare the inflammatory status of children with end-stage renal disease on hemodialysis and those on conservative treatment; and to study the effect of vascular access and cardiac disease on those cytokines.

\section{Patients and Methods}

Sixty patients were included in our study, they were divided into three groups:

Group (A) included thirty children with ESRD, who attended regular sessions of hemodialysis (HD) at Nephrology unit, Cairo University Children's hospital; Group (B) included fifteen patients with CKD stage III and IV, on regular follow up at the Nephrology Clinic and on conservative therapy.

Group (C) included fifteen healthy age and sex matched controls.

As regards inclusion criteria, patients aged 1-16 years with at least six months on HD and CKD stage III, IV. Patients on hemodiafiltration, acute illness in last two months which affect inflammatory markers, patients with chronic diseases that can affect these markers e.g. tuberculosis, systemic vasculitides or patients on immunosuppressive therapy were excluded from our study.

All patients in the study were subjected to the following:

1- Full history taking with special emphasis on the onset of disease, original renal disease and the duration of dialysis, dialysis access either arteriovenous (A-V) fistula or central venous catheter.

2- Anthropometric measurements: weight, height and body mass index (BMI).

3- Complete physical examination especially signs of chronic renal failure such as pallor, oedema and hypertension.

4- Echocardiography

5- Laboratory investigations that included:

- Complete blood count with differential count, complete liver profile that includes the enzymes (alanine amino-transaminase ALT, aspartate transaminase AST, alkaline phosphatase ALP and gamma GT, serum albumin) in addition to hepatitis B and $\mathrm{C}$ viruses status.

- Serum levels of urea, creatinine, albumin, electrolytes, calcium, phosphorus and magnesium (in patients on hemodialysis samples were withdrawn before the midweek dialysis session).

- Measurement of serum levels of inflammatory markers (PTX 3, IL10 and IL 18) using enzyme linked immune-sorbent assay (ELISA). In dialysis patients, two samples were obtained from each patient, a pre and post-dialysis sample.

The study was approved by the Pediatric department and Faculty's Medical Research and Ethics Committee. Informed consents were obtained from all the participants' caretakers after being informed in detail of the purpose and methods of the study. 


\section{Results}

The age distribution of patients is represented in table one, while the distribution of males and females in different groups is shown below in table 2 .
Percentage of different disease aetiology among hemodialysis patients and conservative patients are shown in figure 1 and 2 respectively. The descriptive statistics of the clinical data of patients involved in the study are shown in table 3 .

Table 1: Age distribution of patients included in the study.

\begin{tabular}{|c|c|c|c|}
\hline Group & Number & Mean of age & Standard Deviation \\
\hline Group (A) & 30 & 11.93 years & 3.79 \\
\hline Group (B) & 15 & 8.46 years & 3.63 \\
\hline Group (C) & 15 & 7.93 years & 2.40 \\
\hline
\end{tabular}

Table 2: Sex distribution among the patients of the study.

\begin{tabular}{|c|c|c|c|}
\hline Sex & Group (A) & Group (B) & Group (C) \\
\hline Males & $13(43.30 \%)$ & $8(53.30 \%)$ & $9(60 \%)$ \\
\hline Females & $17(56.60 \%)$ & $7(46.60 \%)$ & $15(100 \%)$ \\
\hline Total & $30(100 \%)$ & $15(100 \%)$ & \\
\hline
\end{tabular}

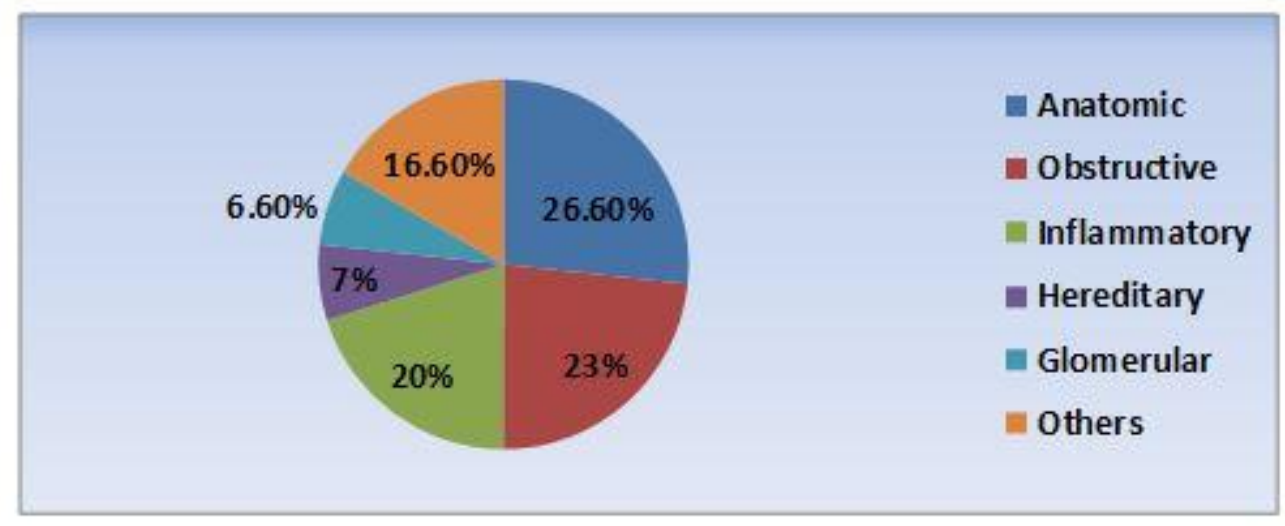

Figure 1: Percentage of different disease aetiology among hemodialysis patients (Group A).

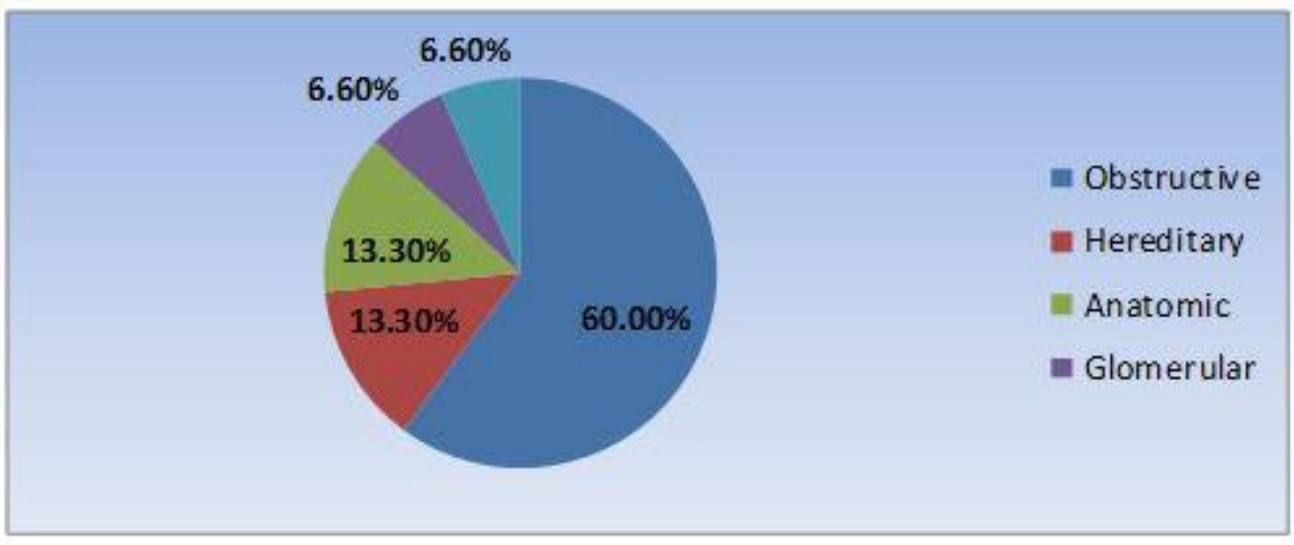

Figure 2: Percentage of different disease aetiology among conservative patients (Group B). 
Table 3: Descriptive statistics of the clinical data of patients involved in the study.

\begin{tabular}{|c|c|c|}
\hline Item & $\begin{array}{c}\text { Hemodialysis Patients } \\
\text { (Group A) } \\
\text { Mean } \pm \text { SD }\end{array}$ & $\begin{array}{c}\text { Conservative Patients } \\
\text { (Group B) } \\
\text { Mean } \pm \text { SD }\end{array}$ \\
\hline Weight & $42 \pm 34.8 \mathrm{Kg}$ & $33.6 \pm 22.6 \mathrm{Kg}$ \\
\hline Height & $148.2 \pm 121 \mathrm{~cm}$ & $121.7 \pm 94.3 \mathrm{~cm}$ \\
\hline Body mass index & $23.37 \pm 7.19$ & $24.1 \pm 8.35$ \\
\hline Systolic blood pressure & $130-160$ & $90-120$ \\
\hline Diastolic blood Pressure & $70-90$ & $50-80$ \\
\hline Vascular Access & $65 \%$ Catheter, 35\% A-V & Not applicable \\
\hline Duration on Hemodialysis & 6 years & Not applicable \\
\hline
\end{tabular}

A.V fistula: arteriovenous fistula

(Twenty five patients on hemodialysis (83.3\%) had systemic hypertension controlled by medications. Twenty four of them $(80 \%)$ had anemia $(\mathrm{Hgb}<10 \mathrm{~g} / \mathrm{dl}$. In conservative patients, two patients $(13.3 \%)$ had systemic hypertension, and nine $(60 \%)$ had anaemia. Associated diseases is included in Table 4 below. While the laboratory data of the patients involved in the study are included in Table 5 below.

Table 4: Descriptive statistics of the associated diseases of patients involved in the study.

\begin{tabular}{|c|c|c|}
\hline Item & HD patients & Conservative patients \\
\hline$\quad$ Cardiomyopathy & $11 / 30(36.60 \%)$ & $2 / 15(13.30 \%)$ \\
\hline$\quad$ Convulsions & $5 / 30(16.60 \%)$ & Negative \\
\hline$\quad$ Hepatitis C & $8 / 30(26.60 \%)$ & Negative \\
\hline$\quad$ Hepatitis B & negative & Negative \\
\hline
\end{tabular}

Table 5: descriptive statistics of the laboratory data of studied patients.

\begin{tabular}{|l|c|c|c|}
\hline \multicolumn{1}{|c|}{ Item } & \multicolumn{1}{|c|}{$\begin{array}{c}\text { Conservative patients } \\
\text { Mean } \pm \text { SD }\end{array}$} & P SD \\
\hline Hemoglobin (g/dl) & $10.26 \pm 4.63$ & $10.36 \pm 4.29$ & 0.307 \\
\hline Total leukocytic count (thousand/mcl) & $6.66 \pm 0.87$ & $7.08 \pm 0.57$ & 0.123 \\
\hline $\begin{array}{l}\text { Platelets } \\
\text { (thousand/mcl) }\end{array}$ & $182.4 \pm 17.60$ & $143.53 \pm 10.41$ & 0.893 \\
\hline Blood urea nitrogen (mg/dl) & $67.36 \pm 8.78$ & $55.4 \pm 18.78$ & 0.117 \\
\hline Creatinine (mg/dl) & $7.7 \pm 4.36$ & $3.6 \pm 1.92$ & 0.653 \\
\hline $\begin{array}{l}\text { Kt/V }= \\
\text { determine adequacy of dialysis. }\end{array}$ & $1.78 \pm 0.17$ & Not applicable & 0.215 \\
\hline Albumin (g/dl) & $3.82 \pm 0.169$ & $3.92 \pm 0.49$ & 0.218 \\
\hline Calcium (mg/dl) & $8.49 \pm 1.83$ & $9.37 \pm 0.62$ & 0.258 \\
\hline Phosphorus (mg/dl) & $4.74 \pm 1.27$ & $5.37 \pm 1.82$ & 0.234 \\
\hline ALP (IU/l) & $521.4 \pm 18.09$ & $452.5 \pm 15.11$ & 0.289 \\
\hline ALT (IU/l) & $24.63 \pm 12.04$ & $31.33 \pm 17.43$ & 0.122 \\
\hline AST (IU/l) & $39.33 \pm 8.43$ & $45.6 \pm 21.89$ & $142.46 \pm 9.40$ \\
\hline Sodium (mEq/l) & $140.8 \pm 13.05$ & $4.68 \pm 1.75$ & 0.146 \\
\hline Potassium(mEq/l) & $4.42 \pm 1$ & & \\
\hline
\end{tabular}

HD: hemodialysis, ALP: alkaline phosphatase, ALT: alanine aminotransferase, AST: aspartate aminotransferase. 
The level of IL18 was significantly higher in the conservative group with a mean of $50.92 \pm 13.69 \mathrm{pg} / \mathrm{ml}$ compared to the control group that had a mean of $2.87 \pm 0.77$ $\mathrm{pg} / \mathrm{ml}$, and was even higher in the hemodialysis group $(256 \pm 435 \mathrm{pg} / \mathrm{ml})$ as shown in table 7 . IL-18 levels were significantly higher in patients who dialyzed using central catheters $(226.4 \pm 98.5 \mathrm{pg} / \mathrm{ml})$, compared to those who dialysed using AV fistulae $(140.2 \pm 53.8 \mathrm{pg} / \mathrm{ml})$ ( $\mathrm{p}$ value 0.02) .

PTX3 levels were significantly higher in the hemodialysis group compared to the conservative group ( $p$ value 0.06 ) as shown in table 7. PTX3 levels were significantly higher in HD patients who dialysed using central catheters with a mean of $6.92 \pm 3.48 \mathrm{ng} / \mathrm{ml}$, compared to those who dialyzed using A.V fistula (mean of $4.36 \pm 2.31 \mathrm{ng} / \mathrm{ml}$ ) (p value 0.04 ).

Table 6: Comparison between pre and post dialysis as regard three laboratory markers.

\begin{tabular}{|c|c|c|c|}
\hline Variable & $\begin{array}{c}\text { Pre-Dialysis } \\
\text { Mean } \pm \text { SD }\end{array}$ & $\begin{array}{c}\text { Post-Dialysis } \\
\text { Mean } \pm \text { SD }\end{array}$ & P-value \\
\hline Pentraxin3 $(\mathbf{n g} / \mathbf{m l})$ & $8.87 \pm 4.37$ & $11.83 \pm 5.24$ & 0.044 \\
\hline Interleukin 18 (pg/ml) & $256 \pm 135$ & $817 \pm 475$ & 0.001 \\
\hline Interleukin 10 (pg/ml) & $1.17 \pm 0.84$ & $1.91 \pm 1.05$ & 0.12 \\
\hline
\end{tabular}

Table 7: Comparison between haemodialysis (pre dialysis level) and conservative patients.

\begin{tabular}{|c|c|c|c|}
\hline Variable & $\begin{array}{c}\text { Hemodialysis } \\
\text { (pre-Dialysis) } \\
\text { Mean } \pm \text { SD }\end{array}$ & $\begin{array}{c}\text { Conservative } \\
\text { Group(B) } \\
\text { Mean } \pm \text { SD }\end{array}$ & P-value \\
\hline Pentraxin 3 (ng/ml) & $8.87 \pm 4.36$ & $1.25 \pm 0.42$ & 0.006 \\
\hline Interleukin18 $(\mathbf{p g} / \mathbf{m l})$ & $256 \pm 435$ & $50.92 \pm 13.69$ & 0.01 \\
\hline Interleukin10 $(\mathbf{p g} / \mathbf{m l})$ & $1.11 \pm 0.67$ & $0.92 \pm 0.15$ & 1.22 \\
\hline
\end{tabular}

There was neither a significant difference between hemodialysis and conservative group values of IL-10, nor between conservative group and controls, yet IL-10 was significantly higher in HD patients who dialysed using central catheters with a mean of $2.98 \pm 1.05 \mathrm{pg} / \mathrm{ml}$ compared to those who dialyzed using A.V fistula with a mean of $1.32 \pm 0.76 \mathrm{pg} / \mathrm{ml}(\mathrm{P}=0.03)$.

Correlation was done between each of the three parameters PTX-3, IL18, IL10 and all other laboratory data of patients included in the study which revealed a significant positive correlation between PTX-3 and IL 18 $(\mathrm{r}=0.5, \mathrm{P}=0.001)$, and a significant negative correlation between PTX3 and IL10 ( $\mathrm{r}=-0.46, \mathrm{P}=0.009)$.

There was also a significant positive correlation between IL18 and PTX3 ( $\mathrm{r}=0.47, \mathrm{P}=0.005)$, and a significant negative correlation between IL18 and IL10 ( $\mathrm{r}=-0.33$, $\mathrm{P}=0.001)$.correlation between IL18 and IL10 ( $r=-0.33$, $\mathrm{P}=0.001)$.

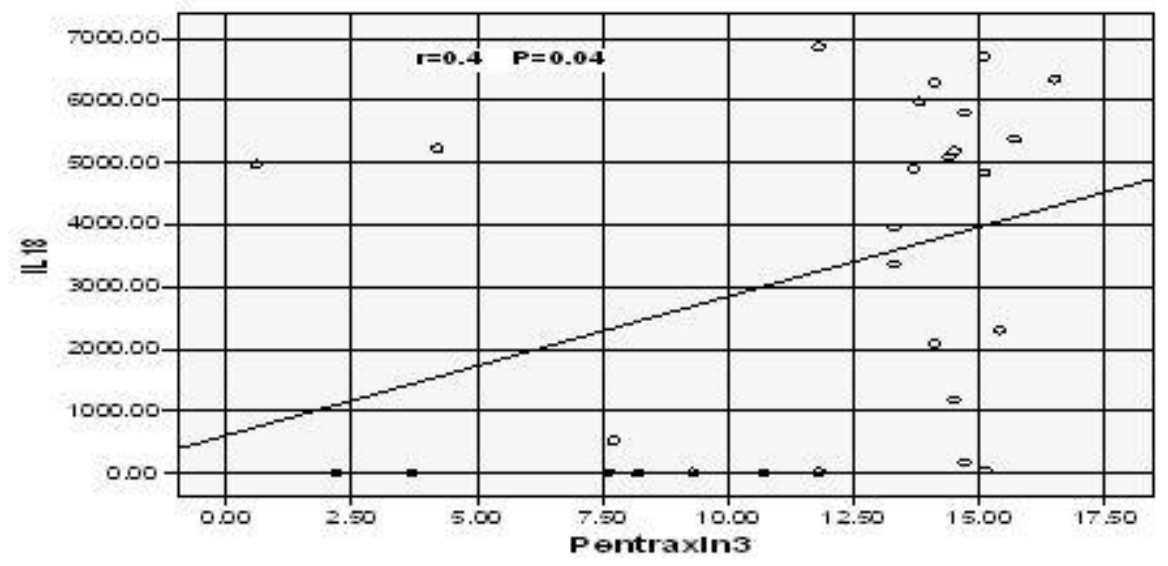

Figure 3: Positive correlation between pentraxin3 and Interleukin18. 


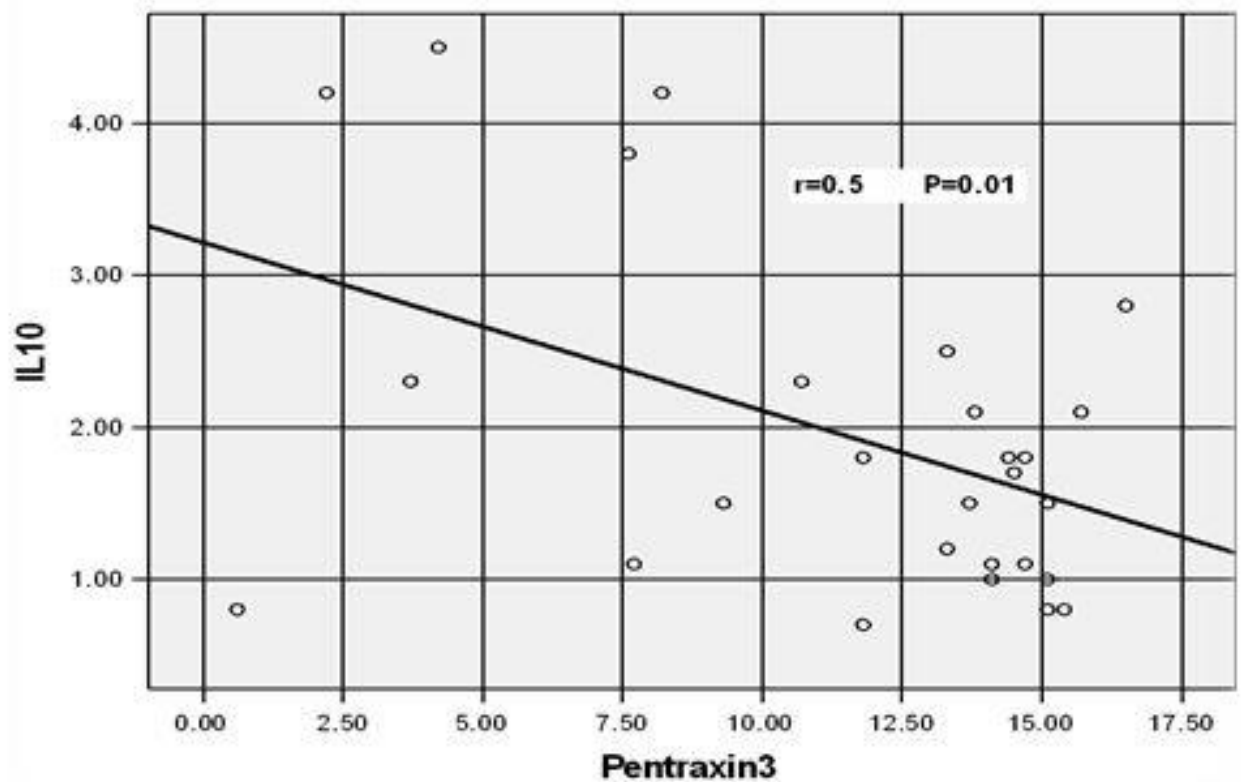

Figure 4: Negative correlation between pentraxin 3 and Interleukin10

In our study, twelve patients $(12 / 30,40 \%)$ had cardiac affection proved by Echocardiography. The mean level of each m.arker was measured before and after HD which revealed that IL18 was markedly elevated in cardiac patients especially after HD with significant $\mathrm{P}$ value of 0.044 .
Correlation was done between three laboratory markers (PTX3, IL18 and IL10) and the fractional shortening, the mean was $34.6 \%$ as an indicator of cardiac function in these patients which revealed a significant negative correlation between IL18 and fraction shortening $(r=-0.5$, $\mathrm{P}=0.04$ ), as shown in figure 5 below.

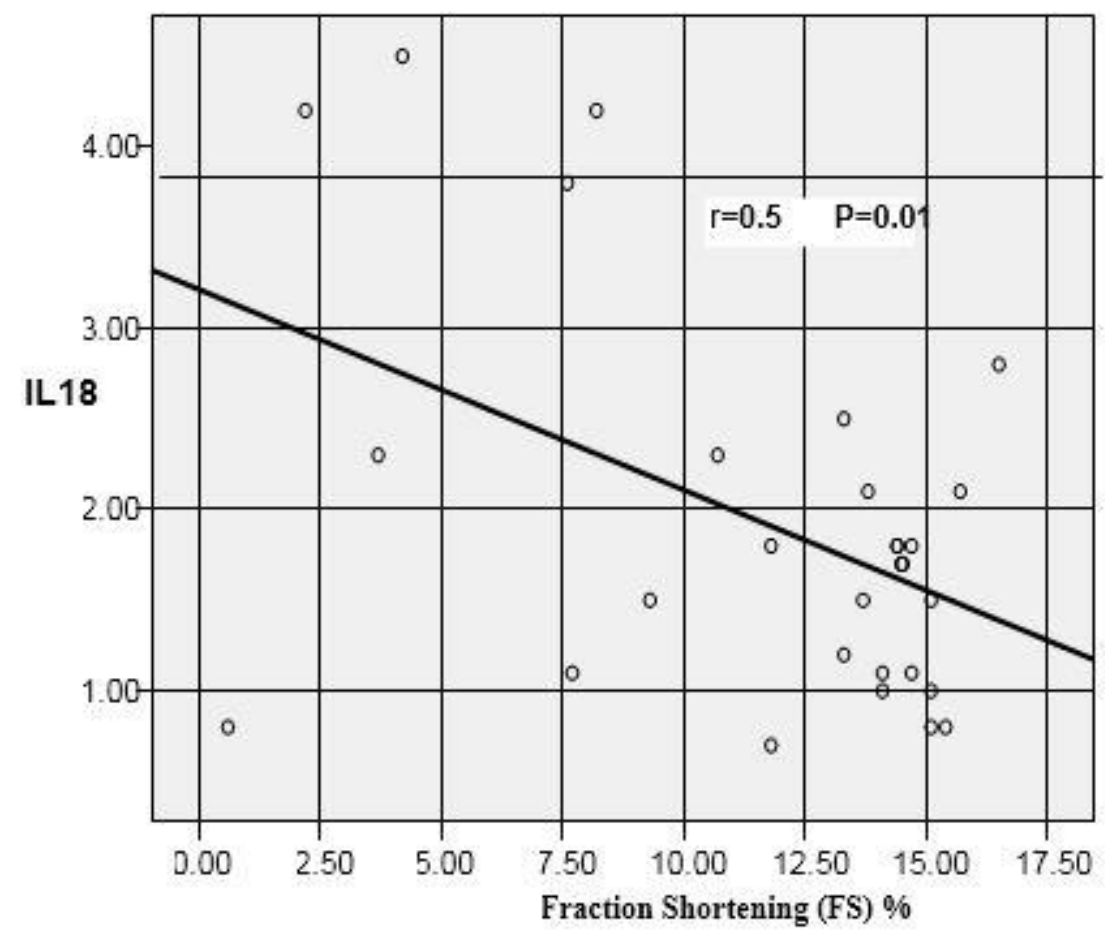

Figure 5: Negative correlation between IL18 and fraction shortening. 


\section{Discussion}

Patients with end stage renal disease (ESRD) strongly exhibit higher serum levels of inflammatory cytokines such as CRP, IL6, Pentraxin 3 and IL18 compared to healthy people, due to their role in the shift to Th1, the induction of IFN- $\gamma$ release demonstrated during dialysis, contact of blood with the membrane of dialyzer, in addition to non-dialysis related factors such as impaired immune response. [13], the hemodialysis (HD) procedure per se has been shown to induce an inflammatory response initiated by factors such as the contact of blood cells with the dialysis membrane and lipopolysaccharide (LPS) from contaminated dialysate [14]. The most commonly used inflammatory marker in clinical practice is C-reactive protein (CRP), which together with interleukin 6 (IL-6), are strong predictors of cardiovascular mortality in the general population, as well as in dialysis patients [15]. However, CRP is not an ideal marker to assess inflammatory reactions during HD because of its delay in response to stimuli and its large inter-individual variability.

In the present study, the mean serum level of PTX-3 was higher among patients on regular hemodialysis, with post-dialysis level $(11.83 \mathrm{ng} / \mathrm{ml})$ compared to pre-dialysis $(8.87 \mathrm{ng} / \mathrm{ml}) \quad(\mathrm{p}$ value 0.044$)$, which reflects the accentuated inflammatory response to hemodialysis. These results are similar to that of Okamura et al.(16), who found a significant increase in plasma level of PTX3 after 4 hours of dialysis session (serial measurement) from 5.8 to $8.4 \mathrm{ng} / \mathrm{ml}$, p value < 0.001 . This is due to HD induced complement activation and activation of peripheral blood mononuclear cells. The two main factors inducing immune activation during HD are blood membrane interaction and subclinical endo-toxinemia from trans-membrane passage of LPS fragments in the dialysate. Similarly, a study of 31 non hospitalized HD patients showed a significant increase in PTX-3 levels after frequent sessions of HD (17) that is consistent with our results.

In our study, the mean serum level PTX-3 in conservative patients (group B) was $1.25 \mathrm{ng} / \mathrm{ml}$ which is much lower than HD (group A), who had a mean of 8.87 $\mathrm{ng} / \mathrm{ml}$ and this is consistent with finding of Tangri et al. [18], who found that HD patients have markedly higher pre-HD concentrations of plasma PTX-3 compared with patients with peritoneal dialysis and CKD stage 5 patients before starting renal replacement therapy. Our finding is also consistent with Beebe et al. [19], who found marked increase in PTX-3 production after a single HD session. Ben et al. [20] documented a rapid and clear increase in plasma PTX-3 level during the first $2 \mathrm{~h}$ of dialysis and is significant after $60 \mathrm{~min}$ of $\mathrm{HD}$, the median peak comes at $180 \mathrm{~min}$ of dialysis $(8.7 \mathrm{ng} / \mathrm{ml})$ in a study done on $22 \mathrm{HD}$ patients. The increase in PTX3 concentration was similar in all sessions of hemodialysis, the mean level of PTX3 increased from 5.8 (3.9-8.1) to $8.4(6.4-10.5) \mathrm{ng} / \mathrm{ml}$, $\mathrm{p}<0.001$, during a standard HD treatment of 4 hours.

In contrast, Hattan et al. [21] found no increase in PTX-3 production after HD. They studied 52 patients with ESRD on regular HD and this is may be due to short duration of dialysis. Patients with chronic kidney disease (CKD) have accelerated atherosclerosis associated with an increase in cardiovascular morbidity and mortality compared to the general population [22]. The traditional risk factors for arteriosclerosis cannot alone explain the high prevalence of cardiovascular disease (CVD) in CKD patients. Recent evidence shows that inflammatory processes play a relevant role in atherogenesis. In dialysis patients, oxidative stress and inflammation are associated with the development of CVD [23].

In the current study, the mean serum level of IL10 in HD (group A) was $1.11 \mathrm{pg} / \mathrm{ml}$ compared to conservative patients (group B) with $0.92 \mathrm{pg} / \mathrm{ml}, \mathrm{P}$ value was not significant 1.22 . There was also no significant difference between conservative patients $0.92 \mathrm{pg} / \mathrm{ml}$ and controls $0.73 \mathrm{pg} / \mathrm{ml}$. Our results are similar to that of Peri et al. [4] who studied 30 patients with ESRD, 16 of them on HD and 14 on conservative treatment and found no difference in the serum levels of IL10 after 3 months of hemodialysis. Our observation indicates a marked abnormality in IL10 synthesis by peripheral blood mononuclear cells in HD patients probably related to transcriptional defect and low IL10 synthesis may contribute to a chronic inflammatory state in these patients by defective feedback inhibition of pro-inflammatory cytokine production [25]. The polymorphism at position1082 of the IL10 gene promoter, which determines a high or low producer phenotype, is predictive for the risk of cardio-vascular events in hemo-dialysis patients. This effect is independent from many accompanying factors such as cholesterol level, patient age, medication or underlying renal disease [26].

Some authors have demonstrated that, even in the absence of catheter-related infection, patients receiving hemodialysis through a catheter had significantly higher serum concentrations of C-reactive protein, suggesting that chronic inflammation could be the reason for their significantly higher mortality rate [27, 28, and 29]. This explains why we found a significantly higher proinflammatory response in those patients who dialyzed using central venous catheters compared to those who used arteriovenous fistulae.

High expression of anti-inflammatory factors such as IL10 seems to limit the progression of cardiovascular morbidity and mortality [30] and this is consistent with our results where twelve patients $(12 / 30,40 \%)$ that had cardiac affection (in the form of cardiomyopathy) proved by Echocardiography, IL10 was significantly lower after $\mathrm{HD}(1.2 \mathrm{pg} / \mathrm{ml})$ than before $(2.7 \mathrm{pg} / \mathrm{ml})$ with a significant $P$ value of 0.02 . In the present study, the mean serum level of IL18 was significantly higher in post dialysis $(817 \pm 475$ $\mathrm{pg} / \mathrm{ml})$ than pre dialysis $(256 \pm 135 \mathrm{pg} / \mathrm{ml})$ with a significant $P$ value of 0.001 . Elevated concentration of IL18 was shown to be a strong predictor of cardiovascular mortality in patients with ESRD due to its involvement in the fibrous plaque stage of atherosclerosis process.

Our results are consistent with that of Wasse et Port [31] who studied 184 patients on HD therapy and found high level of IL18 (676 pg/ml), P value of 0.01due to large sample size. A positive significant correlation between IL18 and duration of dialysis, cholesterol and triglycerides was found. These factors are considered to be major ones 
for cardio-vascular disease. HD catheters are an obvious source of overt infection, although, even without known infection, it has recently been shown that HD catheters contribute to chronic inflammation. The removal of a noninfected, tunneled dialysis catheter and the use of an AV fistula as the permanent dialysis access is associated with a reduction in inflammatory markers [32]. This association with inflammation plays a role in the increased risk of death associated with the use of a dialysis catheter. This is consistent with our results where the mean of serum PTX-3 and IL18 were higher in patients who are dialyzed via central catheter $(6.92 \pm 3.48 \mathrm{ng} / \mathrm{ml}, 226.4$ $\pm 98.5 \mathrm{pg} / \mathrm{ml}$ ) respectively with significant $\mathrm{P}$ value of $(0.04,0.002)$ than those who are dialyzed via AV fistula $(4.36 \pm 2.31 \mathrm{ng} / \mathrm{ml}, 140.2 \pm 53.8 \mathrm{pg} / \mathrm{ml})$. The study done by Inoue et al. [33] also focuses on the association of vascular access type and chronic inflammation, and proved that the vascular access type has a significant impact on the dialysis survival among HD patients.

Hemodialysis patients show serological evidence of an activated inflammatory response as indicated by increase circulating levels of markers of inflammation and pro-inflammatory cytokines including IL18, IL6, TNF- $\alpha$ and PTX-3 [34]. This is consistent with our results where there was a significant positive correlation between PTX3 and IL18 $(\mathrm{r}=0.5, \mathrm{P}=0.001)$.

The cascade of inflammatory factors leading to an acute phase reaction is counter-regulated by the antiinflammatory cytokine interleukin-10 (IL-10) (35). This is consistent with our findings where there was a significant negative correlation between PTX-3 and IL10 $(\mathrm{r}=-0.33, \mathrm{P}=0.001)$.

IL-18 is known to initiate the activation of a chain of proinflammatory cytokines and stimulate Th1 or Th2 response, [36] these processes are considered crucial for acceleration of atherosclerosis triggered by multiple diverse mechanisms [37], which add up to the proinflammatory state associated with renal failure. IL-18 is highly expressed in human coronary plaques and probably plays a role in their destabilization. [38]. Hemodialyzed patients commonly exhibit higher levels of IL18 and have worse left ventricular systolic function compared with those with low levels. [39] This is consistent with our results where there is a significant negative correlation between IL18 and the fraction shortening (FS \%), r=-0.5, $\mathrm{P}=0.02$ and hence Interleukin 18 can be used as a risk factor for cardiac disease in HD patients.

\section{Conclusion}

Children with ESRD had higher post dialysis levels of inflammatory cytokines such as PTX3 and IL 18 than predialysis levels. Also, they had higher levels than conservative patients. No significant difference as regard IL10 in both hemodialysis and conservative patients.

IL10 was negatively correlated with cardio-vascular complications. Fourty percent of patients had cardiovascular lesions proved by ECHO. The use of central venous catheter in HD patients is associated with increase in inflammatory markers. PTX3, IL18 were significantly higher in patients who dialyzed via CVC than those via AV fistula.

\section{References}

1- United States Renal Data System. Annual Data Report. 2012; 34(2):233-238

2- Kopple JD. National kidney foundation K/DOQI clinical practice guidelines for nutrition in chronic renal failure. Am J Kidney Dis. 2001; 37(2):66-70.

3- Douglas DY. Vitamin D Curbs Albuminuria in Kidney Disease.

Medscape Medical News. 2013; 12(3):234-238.

4- Bottazzi B, Garlanda C, Salvatori G, Jeannin P, Manfredi A, Mantovani A.et al. Pentraxins as a key component of innate immunity.

Curr Opin Immunol 2006; 18(1): 10-15.

5- Peri GR, Introna MK, Corradi DU.et al. PTX3, A prototypical long pentraxin, is an early indicator of acute myocardial infarction in humans. Circulation 2010; 102(5): 636-641.

6- Inoue KV, Sugiyama AR, Reid PC.et al. Establishment of a high sensitivity plasma assay for human pentraxin3 as a marker for unstable angina pectoris.

Arterioscler Thromb Vasc Biol 2007; 27(2): 161-167.

7- Latini RP, Maggioni AP, Peri GK.et al Prognostic significance of the long pentraxin PTX3 in acute myocardial infarction.

Circulation 2004; 110(5):2349-2354.

8- Okamura H, Tsutsui H, Komatsu T,et al. Cloning of a new cytokine that induces interferon.

Nature 2005; 378:88-91.

9- Huang HY, Yu HT, Chan SH.et al "Eutopic endometrial interleukin 18 system mRNA and protein expression at the level of endometrial-myometrial interface in adenomyosis patients". Fertil. Steril. 2010; 23(1):123-127.

10- Donnelly RP, Dickensheets HY, Finbloom DS.et al. The interleukin10 signal transduction pathway and regulation of gene expression in mononuclear phagocytes.

J Interferon Cytokine Res 2009; 19(1): 563-573.

11- Moore KW, de Waal MR, Coffman RL.et al Interleukin 10 and interleukin 10 receptor. Cytokines 2001; 19(2):683-765.

12- Boschee, E.D., Cave, D.A., Garros, D. et al. Indications and outcomes in children receiving renal replacement therapy in pediatric intensive care. J Crit Care. 2014; 29: 37-42.

13- Kaysen, "Inflammation nutritional state and outcome in end stage renal disease,"Mineral and Electrolyte Metabolism, 2009; 25: 242-250.

14- Qureshi AR, Alvestrand A, Divino-Filho JC, et al. Inflammation, malnutrition, and cardiac disease as predictors of mortality in hemo-dialysis patients. J Am Soc Nephrol 2002; 13:S28-S36.

15- Alles V, Bottazzi B, Peri G, et al. Inducible expression of PTX3, a new member of pentraxin family in human mononuclear phagocytes.

Blood 2004; 84:3483-3493. 
16- Okamura H, Tsutsui H, Komatsu T,et al. Cloning of a new cytokine that induces interferon.

Nature 2005; 378:88-91

17- Suliman M, Qureshi A, Carrero J, et al. The long pentraxin PTX3 in prevalent hemodialysis patients: associations with comorbidities and mortality.

2008; 101:397-405

18- Tangri N, Stevens LA, Griffith J, et al. A predictive model for progression of chronic kidney disease to kidney failure.

JAMA. 2011; 305:1553-1559

19- Beebe AM, Cua DJ, DE waal, et al. The role of interleukin10 in autoimmune disease: systemic lupus erythematosus (SLE) and multiple sclerosis (MS). Cytokine Growth Factor Rev 2002; 13: 403- 412.

20- Ben-Dov IZ, Galitzer H, Lavi-Moshayoff V et al. The parathyroid is a target organ for FGF23 in rats. J Clin Invest 2007; 117: 4003-4008.

21- Hattan, E., Chalk, C. \& Postuma, R. B.et al. Is there a higher risk of restless legs syndrome in peripheral neuropathy? Neurology 2009; 72, 955-960.

22- Besarab A, Amin N, Ahsan M et al. Optimization of epoetin therapy with intravenous iron therapy in hemodialysis patients.

J Am Soc Nephrol 2010; 11: 530-538.

23- Foley RN, Parfrey PS, Sarnak MJ, et al. Cardiovascular disease in chronic renal disease: Clinical epidemiology of cardiovascular disease in chronic renal disease. Am J Kidney Dis 2008; 32:S112-S119

24- Peri G, Introna M, Corradi D, et al. PTX3, A prototypical long pentraxin, is an early indicator of acute myocardial infarction in humans. Circulation 2010; 102: 636-641.

25- Girndt M, Kohler H, Schiedhelm Weick E, et al. Production of interleukin 6, tumor necrosis factor alpha and interleukin 10 in vitro correlates with the clinical immune defect in chronic hemo-dialysis patients. Cytokines 2008; 47:559-565.

26- Rambod M, Kovesdy CP, Kalantar-Zadeh K.et al Combined high serum ferritin and low iron saturation in hemo-dialysis patients: the role of inflammation. Clin J Am Soc Nephrol 2008; 3: 1691-1701

27- Goldstein SL, Ikizler TA, Zappitelli M, Silverstein DM, Ayus JC. 2009. Non-infected hemodialysis catheters are associated with increased inflammation compared to arteriovenous fistulas.

Kidney Int. 76:1063-1069

\section{Declaration}

\section{Ethics approval and consent to participate}

This study protocol and the consents were approved and deemed sufficient by Ethical Committee of Pediatric Department, Faculty of Medicine, Cairo University. And informed written consent was obtained in every case from their legal guardians.

\section{Funding}

The authors declare that they didn't receive any financial support from agencies or others.

\section{Conflict of interest}

No

\section{Acknowledgements}

We would like to thank all patients and their family members for their valuable contributions to the study.
28- Al Saran K, Sabry A, Shalaby M, Al Sherbeiny S, Abdelkader M. Level of C-reactive protein in chronic hemodialysis patients: a comparative study between patients with non-infected catheters and arteriovenous fistula in a large Saudi hemodialysis center.

Ther. Apher. Dial. 2013, 17:35-39.

29- Yeun JY, Levine RA, Mantadilok V, Kaysen GA. $\mathrm{C}$ - reactive protein predicts all-cause and cardiovascular mortality in hemodialysis patients.

Am. J. Kidney Dis. 2000, 3:469-476.

30- Goldstein SL, Ikizler TA, Zappitelli M, et al. Non infected HD catheters are associated with increased inflammation compared to arterio-venous fistulas.

Kid Int 2009; 76:1063-1069.

31- Wasse JD, Port FK. The impact of vascular access Nephrol Dial Transplant 2013; 12: 657-659.

32- Wong CJ, Moxey-Mims M, Jerry-Fluker J, et al. $\mathrm{CKD}$ in children, prospective cohort study: a review of current findings. Am J kidney Dis 2012; 60:1002.

33- Inoue K, Sugiyama A, Reid PC, et al. Establishment of a high sensitivity plasma assay for human pentraxin3 as a marker for unstable angina pectoris. Arterioscler Thromb Vasc Biol 2007; 27: 161-167.

34- Bash LD, Erlinger TP, Coresh J, et al. Inflammation, haemostasis, and the risk of kidney function decline in the Atherosclerosis Risk in Communities (ARIC) Study.

Am J Kidney Dis 2009; 53:596-605.

35- Akdis CA, Blaser K. Mechanisms of interleukin 10 mediated immune suppression.

Immunology 2001; 103:131-136.

36- Weaver, C. T., Harrington, L. E., Mangan, P. R., Gavrieli, M. \& Murphy, K. M. Th17: an effector CD4 T cell lineage with regulatory $\mathrm{T}$ cell ties.

Immunity, 2006, 24, 677-688.

37- Kurts, C., Panzer, U., Andres, H.-J. \& Rees, A. The immune system and kidney disease: Basic concepts and clinical implications.

Nat. Rev. Immunol, 2013, 13, 738-753.

38- Mallat, Z. et al. Expression of interleukin-18 in human atherosclerotic plaques and relation to plaque instability. Circulation 2001, 104, 1598-1603.

39- Blankenberg S, Tiret L, Bickel C, et al. Interleukin18 is a strong predictor of cardiovascular death in stable and unstable angina. Circulation 2002; 106:24-30. for haemodialysis on patient morbidity and mortality. 